\title{
Hock Injury Prevalence and Associated Risk Factors on Organic and Nonorganic Dairy Farms in the United Kingdom
}

\author{
K. M. D. Rutherford, ${ }^{1}$ F. M. Langford, M. C. Jack, L. Sherwood, A. B. Lawrence, and M. J. Haskell \\ Animal Behaviour and Welfare, Sustainable Livestock Systems, Scottish Agricultural College, West Mains Rd., Edinburgh, EH9 3JG, Scotland
}

\begin{abstract}
The presence of hock injury was assessed in the milking herds of 80 dairy farms (40 organic, 40 nonorganic) across the United Kingdom. A wide range of information on farm management and husbandry was gathered via interview to assess the factors contributing to hock damage for all 80 farms, and a comprehensive building appraisal was conducted for 40 farms visited during the winter housing period. The prevalence of hock lesions was lower on organic compared with nonorganic farms (37.2 vs. 49.1\%). Prevalence of hock damage was greater in the spring than fall (59.9 vs. $21.6 \%$ ) and cows housed in free-stalls had a greater prevalence of hock lesions than those housed on straw (46.0 vs. $25.0 \%$ ). Prevalence of hock damage increased with lactation number. In the analysis of fall/spring data, the age first mated, herd biosecurity, duration of summer grazing, and cow milk yield were significant factors relating to herd hock damage. Larger herds had a greater proportion of cows with hock swellings. Farms with a shorter calving interval had more cows with hock swellings. Factors relating to housing conditions that were positively associated with the prevalence of hock damage were low feed face space per cow, inferior passageway cleanliness, low total standing area per cow, and the type of bedding added to the free-stall. To assess whether free-stall versus straw-pen or organic versus nonorganic farms had different sets of risk factors, the data were reanalyzed for these types separately. For the straw-pen farms a high culling rate was associated with more hock damage. Within nonorganic farms, the length of summer grazing was significant, with longer periods meaning less hock injury. The prevalence of hock injuries on many UK farms, both organic and nonorganic, exceeded levels that are deemed acceptable for cow comfort. Efforts are needed to improve housing standards to reduce the prevalence of hock injury and consequently improve cow welfare.
\end{abstract}

Received November 9, 2007.

Accepted February 26, 2008

${ }^{1}$ Corresponding author: kenny.rutherford@sac.ac.uk
Key words: dairy cow, hock injury, organic production, welfare

\section{INTRODUCTION}

Schemes assessing cow welfare on farms have shifted their emphasis from resource-based measures to animal-based measures (Whay et al., 2003; Haskell et al., 2006). This shift reflects the perception that many of the welfare outcomes that vary between farms do so as a result of the complex interplay of numerous factors relating to the animals themselves (breed, age, and temperament), the standard of housing and husbandry, and the attitudes of stock handlers and farm owners. Because of this complexity it is now better appreciated that provision of a defined physical environment is not sufficient to ensure good welfare.

Freedom from injury is an important part of farm animal welfare in any housing system. In dairy cows, injuries as a result of the physical environment are most common around the tarsal (hock) joint. The extent to which hock damage is painful or otherwise unpleasant for the individual cow (i.e., the extent to which such lesions are a causal variable in relation to welfare, as opposed to merely an indicator variable: sensu Fayers and Hand, 2002) remains largely unknown. Moreover, it is reasonable to surmise that the degree of hock damage reflects the degree of comfort/discomfort associated with the lying substrate available. Because dairy cows can spend more than $13 \mathrm{~h} / \mathrm{d}$ lying down (Drissler et al., 2005), the comfort afforded them by the lying substrate is an important determinant of overall welfare. Bodily injuries have been used widely in on-farm dairy cow welfare assessments (Main et al., 2003a; Haskell et al., 2006; Thomsen et al., 2007). Housing system has a major influence on the prevalence of hock injuries in dairy cows. Cows housed in free-stall-based systems more frequently had injured or swollen knees and hocks than cows housed in straw-pen systems (Livesey et al., 2002; Haskell et al., 2006). Most cows in free-stall housing systems had lesions of some sort (Weary and Taszkun, 2000; Wechsler et al., 2000).

Organic principles are intended to ensure a higher standard of care than that which exists in nonorganic 
husbandry. A component of this putative higher standard is better housing conditions. For dairy cows in the UK, the regulations contain few specific requirements in relation to housing. For livestock, housing conditions should meet the "behavioural needs as regards appropriate freedom of movement and comfort" and that generally the stocking density "shall provide for the comfort and well-being of the animals" (CEC, 2004). For dairy cows, the stocking density during housing must be $>6 \mathrm{~m}^{2}$ per cow; however, no prescriptions are made as to type or quality of housing (straw-pen vs. free-stalls, or particular free-stall dimensions).

This study aimed to compare animal-based measures of dairy cow welfare on organic and nonorganic farms. Another aim was to gather a large amount of data about other farm characteristics to better understand the factors that influence the welfare outcomes recorded.

\section{MATERIALS AND METHODS}

\section{Farm Recruitment and Characteristics}

Organic dairy farmers were recruited from the membership lists of organic producer/certifier groups (Soil Association, Organic Milk Suppliers Co-operative, and Scottish Organic Producers Association). All organic farms had been certified organic for 2 yr before the study. Initial contact letters were sent out to all farmers on these lists. Farmers who wished to participate were asked to complete a short form to provide certain details about their farm. A total of 355 initial contact letters were sent, yielding 102 positive replies. The farms used were limited to those that had predominantly Holstein/ Holstein-Friesian animals and had a herd size of $>50$ cows. No zero-grazing farms were included and all participating farms kept cows housed for at least part of the winter period. All farms milked their cows twice daily in the morning and afternoon. On these criteria, 50 of the 102 farms were identified as suitable and the final 40 were chosen. It was not possible to fully establish how representative of the national population of organic dairy farms were, because the necessary information at the national level is not available.

The design of the study required that for each organic farm there was a matching nonorganic farm. The farms were matched on housing type (free-stall or straw-pen), herd size, genetic merit, or secondarily milk yield, location, and local rainfall. Farms had matching genetic merit if their mean Profitable Lifetime Index (PLI) or Profit Index (PIN) values were within 1 standard deviation (calculated using data from the UK national herd) of each other. Nonorganic farms that matched these requirements were recruited through Scottish Agricultural College contacts in the dairy industry and a national dairy consultancy firm (Kingshay Farming
Trust). Approximately 500 letters were sent to recruit the final 40 nonorganic farms. Farms were located from lowland Scotland to the south coast of England.

\section{Farm Visits}

Every farm was visited once during the fall (September to October) and once during the spring (March to June). Forty of the farms were visited on one additional occasion during the winter housing period. Matched pairs of organic and nonorganic farms were visited within a 2 -wk period.

Assessment of hock condition was one of the animalbased health- and welfare-related measures score, which included locomotion scoring, BCS, cow cleanliness, and analysis of cow behavior.

Every farmer was interviewed about farm management, housing, husbandry, and animal treatment practices during one of the farm visits. In addition to the information from the interview, a building examination was carried out, which involved a selection of building measurements (e.g., free-stall dimensions, feed face length) on the 40 farms visited during winter housing.

\section{Hock Scoring}

The condition of both hocks was recorded as either sound (hock in good condition with either no hair damage or evidence of reduction in hair length that had not progressed to reveal bare skin) or damaged (hair loss had progressed to leave bare patches of skin or an abrasion was present) for each cow as she stood in the parlor for milking. Scoring was only carried out within an area of the leg from around $7.5 \mathrm{~cm}$ below the lateral surface of the tarsal joint to $7.5 \mathrm{~cm}$ above the level of the tuberosity of calcaneous (point of hock). Injuries outside this area were not included, although injuries to the medial surface of the joint were included. Before the on-farm stage, observers were trained in the hock scoring method. The interobserver reliability was $84 \pm 5 \%$. The presence of any swelling on either hocks or knees was recorded. Because it was not always possible to manually manipulate hocks and it was impossible to touch knees, a swelling was only recorded if it was obvious through visual inspection. Hock or knee swellings were scored as present or absent on each limb. The number of animals scored for hock lesions and hock swellings was different because sometimes the hock was too dirty to readily identify whether a lesion was present, but the presence or absence of a swelling could still be ascertained in these animals. The identity (freeze brand, ear tag number) of each cow was recorded in the parlor during milking, allowing information such as lactation number for analysis. 


\section{Data Analysis}

Genstat (Genstat, 8th ed., Lawes Agricultural Trust, VSN International Ltd., Oxford, UK) was used for all statistical analyses. Generalized linear mixed models (GLMM) were fitted to hock score (with a binomial distribution, sound vs. damaged) data to identify the factors influencing the prevalence of hock damage. Basic graphs were used to assess linearity between the response and each of the explanatory variables recorded during the project. Continuous nonlinear variables were split into quartiles, resulting in factors with 4 levels. When an explanatory variable varied linearly with the response it was entered into the analysis as a variate; otherwise, it was entered into the analysis as a factor. Discrete explanatory variables (organic vs. nonorganic) were analyzed as factors.

Preliminary univariate GLMM analysis was undertaken with each explanatory variable (both variates and factors as fixed effects to identify variables that explained variation in hock damage prevalence). The Random model included pair, farm, visit order and cow. Explanatory variables that were significant at $P<0.25$ within univariate analyses were considered in multivariable models.

Models were built using forward stepwise techniques, adding in each explanatory variable to the fixed-effect model in turn. Explanatory variables with the lowest $P$-value from the univariate analyses were added to the multilevel model first. Those explanatory variables having the same $P$-value in the univariate analyses were added in order of the highest Wald-statistic value from the univariate analysis. Variables within the final model were chosen based on their additional significance when all other explanatory variables in the model had been fitted (i.e., on the adjusted sum of squares). During the model building process, explanatory variables that shared variation were tested individually in the model and the variable explaining more of the variation was kept in the model, with the other being discarded. In addition, Spearman's rank correlations were used to identify relationships between explanatory variables. This process eventually led to models that remained stable regardless of variable order.

The goodness of fit for each model was assessed by calculating sensitivity (the proportion of hock damaged cows that were correctly predicted damaged) and specificity (the proportion of sound cows scores that were correctly predicted sound). All models presented reached at least 0.65 in both specificity and sensitivity to be regarded as having an acceptable level of goodness of fit.
Table 1. Basic descriptive statistics (median $\%, \pm$ interquartile range in parentheses) for prevalence of hock damage and swelling

\begin{tabular}{lccc}
\hline Farm type $^{1}$ & Fall & Winter & Spring \\
\hline All & & & \\
Damage & $8.8 \pm 15.9$ & $33.6 \pm 46.4$ & $40.0 \pm 48.6$ \\
& $(0.0,74.3)$ & $(2.0,89.4)$ & $(1.1,91.6)$ \\
Swelling & $1.4 \pm 2.9$ & $2.17 \pm 3.43$ & $2.34 \pm 6.73$ \\
& $(0.0,14.9)$ & $(0.0,16.7)$ & $(0.0,25.5)$ \\
Organic straw-pen & & & \\
Damage & $1.7 \pm 3.4$ & $9.1 \pm 14.1$ & $8.6 \pm 21.1$ \\
& $(0.0,7.4)$ & $(2.0,25.8)$ & $(1.6,40.0)$ \\
Swelling & $0.01 \pm 0.84$ & $0.00 \pm 0.89$ & $0.77 \pm 1.59$ \\
& $(0.0,1.4)$ & $(0.0,1.4)$ & $(0.0,2.2)$ \\
Nonorganic straw-pen & & & \\
Damage & $2.9 \pm 7.7$ & $26.1 \pm 19.4$ & $21.4 \pm 26.9$ \\
& $(0.0,25.7)$ & $(2.2,75.0)$ & $(2.6,47.3)$ \\
Swelling & $0.51 \pm 0.69$ & $0.85 \pm 0.83$ & $0.51 \pm 1.83$ \\
& $(0.0,1.8)$ & $(0.0,1.4)$ & $(0.0,3.5)$ \\
Organic free-stall & & & \\
Damage & $7.2 \pm 8.6$ & $46.9 \pm 47.1$ & $42.8 \pm 42.3$ \\
& $(0.4,29.7)$ & $(4.3,79.2)$ & $(8.2,79.2)$ \\
Swelling & $0.78 \pm 1.98$ & $2.83 \pm 2.6$ & $3.00 \pm 6.32$ \\
& $(0.0,7.3)$ & $(0.4,9.3)$ & $(0.0,14.5)$ \\
Nonorganic free-stall & & & \\
Damage & $18.1 \pm 21.3$ & $55.7 \pm 32.0$ & $64.6 \pm 46.8$ \\
Swelling & $(0.0,74.3)$ & $(26.3,89.4)$ & $(1.1,47.3)$ \\
& $3.1 \pm 4.33$ & $5.09 \pm 7.9$ & $4.69 \pm 7.17$ \\
& $(0.0,14.9)$ & $(0.0,16.7)$ & $(0.0,25.5)$ \\
\hline 1 & & &
\end{tabular}

${ }^{1}$ Farm type included straw-pen or free-stall housing on organic or nonorganic farms.

\section{RESULTS}

Across all the farms visited there was substantial variation in the prevalence of hock damage (Table 1). Knee swellings were too infrequently scored to make analysis possible. Overall, the prevalence of hock lesions (organic $=37.2 \%$, nonorganic $=49.1 \% ; P=0.002$ ) and hock swellings (organic $=4.6 \%$, nonorganic $=8.3 \%$; $P<0.001)$ was lower on organic compared with nonorganic farms.

Analysis of all 80 farms for the fall and spring visits (Table 2) and for the subset of 40 visited in the winter (Table 3) identified several farm and cow characteristics that were associated with the prevalence of hock damage. There was a large difference between fall and spring visits, with a greater prevalence of hock injury following the winter housing period (59.9\%) than following the summer period of access to pasture (21.6\%). Hock condition in the fall/spring and winter visits was affected by housing type, with cows housed on freestalls (46.0 vs. $25.0 \%$ ) having a much greater prevalence of hock damage. Lactation number of the cow featured in both the fall/spring and winter analyses with older cows having a greater prevalence of hock damage $(\sim 50$ vs. $41 \%$ ) than cows with $<5$ lactations. In the fall/spring analysis, age first mated ( 54.5 for $<14$ mo vs. $24.9 \%$ for $\geq 16$ mo), biosecurity status (herd open vs. closed; 49.1 vs. $31.1 \%$ ), number of months of summer grazing (53.4 
Table 2. Factors affecting hock injuries (damage or swelling) in the fall and spring ${ }^{1}$ for 80 herds

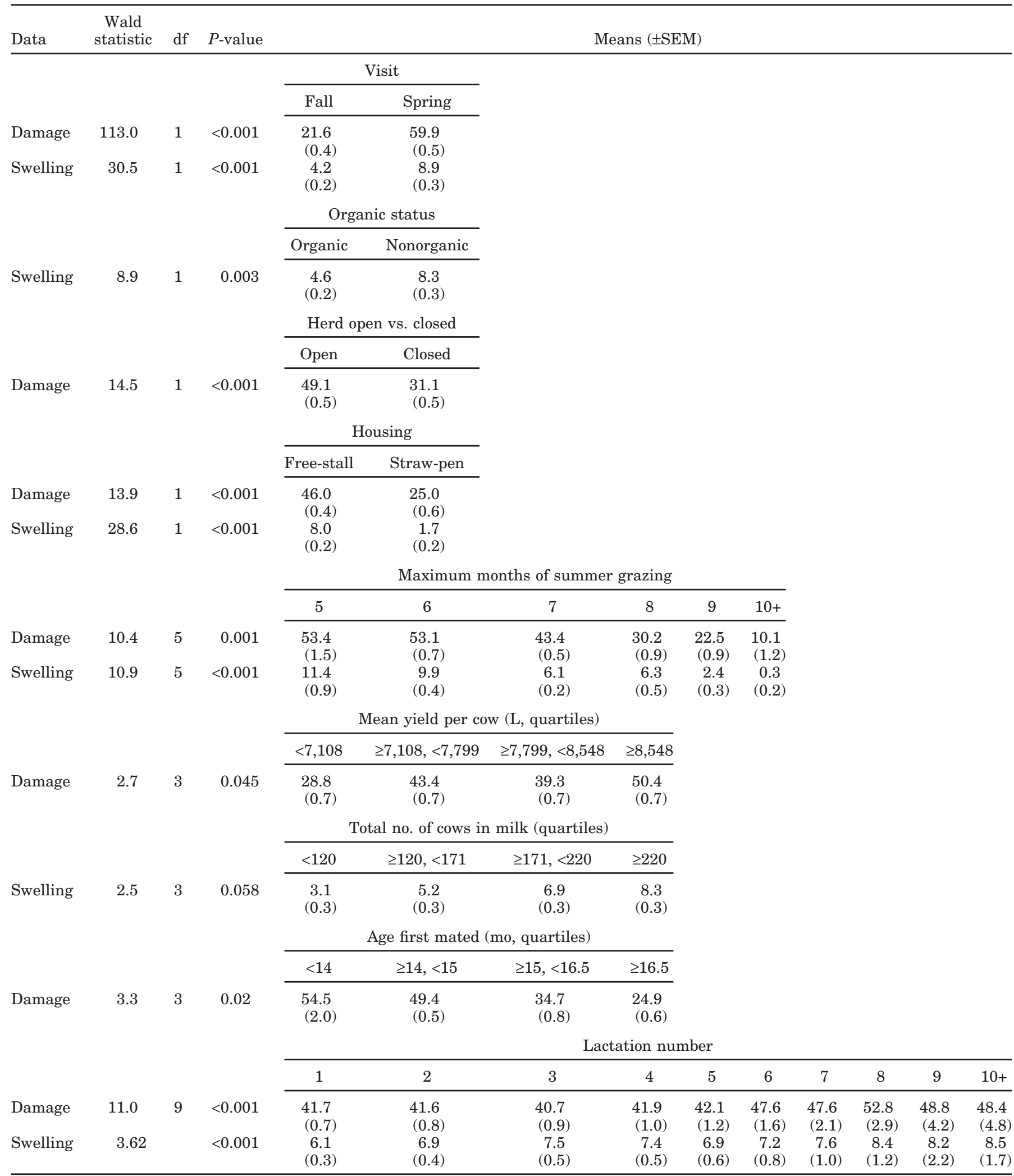

\footnotetext{
${ }^{1}$ Hock damage model: sensitivity $=0.72$, specificity $=0.72$; hock swelling model: sensitivity $=0.65$, specificity $=0.66$.
} 
Table 3. Factors affecting hock injuries (damage or swelling) in the winter ${ }^{1}$ for 40 herds

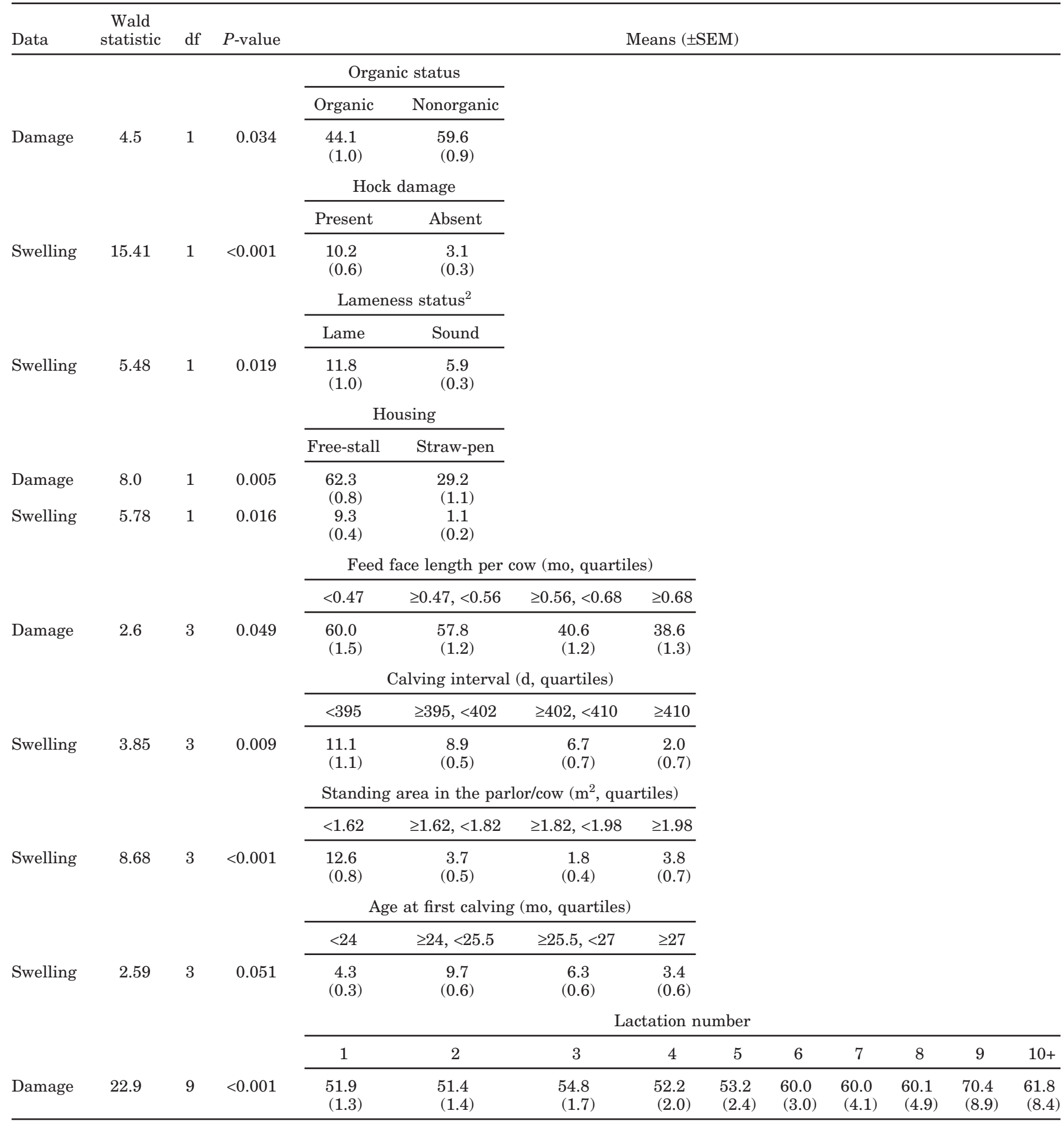

\footnotetext{
${ }^{1}$ Hock damage model: sensitivity $=0.77$, specificity $=0.71$; hock swelling model: sensitivity $=0.67$, specificity $=0.70$.

${ }^{2}$ Lameness was scored on a 4-point scale (simplified from the previously used scale: Haskell et al., 2006). For purposes of analysis, scores 1 and $2=$ sound and scores 3 and $4=$ lame.
}

for 5 mo vs. $10.1 \%$ for $\geq 10 \mathrm{mo}$ ), and herd-average milk yield ( 28.8 for $<7,108 \mathrm{~L}$ vs. $50.4 \%$ for $\geq 8,548 \mathrm{~L}$ ) related to herd hock damage. In the winter analysis, organic cows were less likely to have damaged hocks (44.1 vs. $59.6 \%$ ), and cows with less space to feed had more hock damage $(60.0$ for $<0.47 \mathrm{~m}$ vs. $38.6 \%$ for $\geq 0.68 \mathrm{~m}$ ). 
Analyses were carried out separately for free-stall and straw-pen farms visited in the winter (Table 4). As with the full winter analysis, organic status was associated with decreased hock damage prevalence in both individual free-stalls (56.4 vs. $66.4 \%)$ and strawpen $(21.0$ vs. $38.6 \%)$ analyses. Lactation number was associated with hock damage in straw-pens (21.5 for first lactation vs. $41.9 \%$ for sixth and seventh lactations). On free-stall farms, 3 factors relating to housing conditions related to hock condition: passageway cleanliness (farms with dirty passageways had more cows with hock lesions; 52.5 for score 2 vs. $83.2 \%$ for score 4 ); total standing area per cow (smaller area per cow correlated with more hock damage; 83.0 for $<3.84 \mathrm{~m}^{2}$ vs. $31.6 \%$ for $\geq 5.60 \mathrm{~m}^{2}$ ); and the type of bedding added to the free-stall (cows with straw on their free-stalls had less hock damage than those with sawdust; 65.5 vs. $50.2 \%$ ). For the straw-pen farms it was found that farms with a high culling rate had more hock damage (14.4 for $<0.17$ vs. $37.3 \%$ for $\geq 0.30$ ).

To investigate whether organic and nonorganic farms had different sets of risk factors, the data were reanalyzed separately for the 2 farm types (Table 5). The effects of timing of visit, housing type, and lactation number were consistent between organic and nonorganic farms. Within nonorganic farms the length of summer grazing was important, with longer periods meaning less hock injury (52.3 for 5 mo vs. $26.5 \%$ for $10 \mathrm{mo}$ ).

Although far fewer cows overall were scored with hock swellings than other hock damage there was still variability between farms for the prevalence of swellings (Table 1). For the fall/spring analysis of all 80 farms (Table 2), as with hock damage, a greater prevalence of hock swellings was found in the spring compared with fall (4.2 vs. $8.9 \%)$, in free-stall (8.0 vs. $1.7 \%$ ) compared with straw-pens, when the cows were kept outside for a shorter period during the summer (11.4 for 5 mo vs. $0.3 \%$ for $\geq 10 \mathrm{mo}$ ), and in cows with a higher lactation number (6.1 for first lactation vs. $8.5 \%$ for $\geq$ tenth lactation). Additionally, organic status (organic cows had fewer swellings; 4.6 vs. $8.3 \%$ ) and herd size (larger herds had a greater proportion of cows with hock swellings; 3.1 for $<120$ cows vs. $8.3 \%$ for $\geq 220$ cows) were significant for swellings alone.

Within the winter analysis (Table 3), housing type and standing area in the parlor (a smaller area being associated with more hock swellings; 9.3 for free-stalls vs. $1.1 \%$ for straw pens and 12.6 for $<1.62 \mathrm{~m}^{2}$ vs. $3.8 \%$ for $\geq 1.98 \mathrm{~m}^{2}$ ) were related to the herd level of hock swellings. Farms with a shorter calving interval had more cows with hock swellings (11.1 for $<395$ vs. $2.0 \%$ for $\geq 410 \mathrm{~d}$ ). If an individual cow had other hock lesions or was classified as lame on the basis of a locomotion score, it was more likely to have a swollen hock (10.2 vs. $3.1 \%$ for hock lesions present or absent; 11.8 vs. $5.9 \%$ for lameness present or absent).

As with hock damage score, the swelling data were analyzed separately for free-stall vs. straw-pen farms (Table 4) and organic vs. nonorganic farms (Table 5). The level of hock swellings on straw-pen farms was too low to generate a model with the appropriate goodness of fit. Yet, several factors specific to free-stall farms were identified as risk factors for hock swellings. Within the free-stall farms during the winter, average milk yield per cow ( 4.2 for $<7,328$ vs. $12.2 \%$ for $\geq 8,753 \mathrm{~L}$ ) and space at the feed bunk face $(11.5 \%$ for $\geq 0.47$ and $<0.54 \mathrm{~m}$ vs. $7.6 \%$ for $\geq 0.6 \mathrm{~m}$ ) related to hock swellings, with greater production levels or restricted feed face length per cow being associated with more swellings. The prevalence of hock swellings linearly decreased as average age at first calving increased $(12.5$ for $<23$ mo vs. $4.6 \%$ for $\geq 27 \mathrm{mo}$ ).

\section{DISCUSSION}

Overall, the data suggest that organic farming has a beneficial impact on hock condition in dairy cows. To what extent this is a direct consequence of organic regulations or results more generally from the attitudes of organic farmers remains uncertain. Factors such as months outside on pasture, age first mated, and milk yield, which appear in the explanatory model, differ between organic and nonorganic in the direction expected to benefit organic cows (our unpublished data); that is, the organic farms kept cows out longer during the summer ( 7.6 vs. 6.5 mo), mated heifers later (16.4 vs. $15.1 \mathrm{mo}$ ), and had lower milk yield (7,004 vs. 8,436 L). Analysis of cow locomotion scores carried out during the same farm visits (Rutherford et al., accepted) showed a similar outcome for cow lameness. Also, similarly to the lameness data, this study has highlighted the substantial gap that exists between the best and worst farms. Some organic farms had a high prevalence of hock damage, indicating that organic certification, although having a beneficial impact, does not always necessarily ensure cow comfort.

In support of previous studies (Livesey et al., 2002; Haskell et al., 2006), cows housed in free-stalls during the winter had more hock damage than cows housed in straw-pens. Behavioral studies show that cows in straw-pens spent more time lying on straw (Singh et al., 1993) and were less lame (Haskell et al., 2006); together these related findings show that cow comfort was improved.

Also in support of previous studies (Weary and Taszkun, 2000; Haskell et al., 2006), older cows showed some degree of hock damage. Although hock condition 
Table 4. Factors affecting hock injuries (damage or swelling) on free-stall (F) or straw-pen (SY) farms in the winter ${ }^{1}$

\begin{tabular}{|c|c|c|c|c|c|c|c|c|c|c|c|c|c|}
\hline Data & $\begin{array}{c}\text { Wald } \\
\text { statistic }\end{array}$ & $\mathrm{df}$ & $P$-value & \multicolumn{10}{|c|}{ Means $( \pm$ SEM $)$} \\
\hline & & & & \multicolumn{2}{|c|}{ Organic status } & & & & & & & & \\
\hline F-Damage & 4.7 & 1 & 0.031 & $\begin{array}{l}56.4 \\
(1.2)\end{array}$ & $\begin{array}{c}66.4 \\
(1.0)\end{array}$ & & & & & & & & \\
\hline \multirow[t]{2}{*}{ SY-Damage } & 68.8 & 1 & $<0.001$ & $\begin{array}{l}21.0 \\
(1.4)\end{array}$ & $\begin{array}{c}38.6 \\
(1.8)\end{array}$ & & & & & & & & \\
\hline & & & & Sawdust & Straw & & & & & & & & \\
\hline \multirow[t]{2}{*}{ F-Damage } & 69.4 & 1 & $<0.001$ & $\begin{array}{c}65.5 \\
(0.8)\end{array}$ & $\begin{array}{c}50.2 \\
(1.7)\end{array}$ & & & & & & & & \\
\hline & & & & \multicolumn{3}{|c|}{ Cleanliness of the passageways ${ }^{2}$} & & & & & & & \\
\hline F-Damage & & & & $<3.84$ & $\geq 3.84,<5.06$ & $\geq 5.06,<5.60$ & $\geq 5.60$ & & & & & & \\
\hline \multirow[t]{3}{*}{ F-Damage } & 20.2 & 3 & $<0.001$ & $\begin{array}{c}83.0 \\
(1.2)\end{array}$ & $\begin{array}{c}62.5 \\
(1.5)\end{array}$ & $\begin{array}{c}60.2 \\
(1.3)\end{array}$ & $\begin{array}{c}31.6 \\
(2.0)\end{array}$ & & & & & & \\
\hline & & & & \multicolumn{4}{|c|}{ Step height of the free-stalls (cm, quartiles) } & & & & & & \\
\hline & & & & $<0.19$ & $\geq 0.19,<0.22$ & $\geq 0.22,<0.25$ & $\geq 0.25$ & & & & & & \\
\hline \multirow[t]{3}{*}{ F-Swelling } & 2.33 & 3 & 0.072 & $\begin{array}{l}14.4 \\
(1.1)\end{array}$ & $\begin{array}{c}7.4 \\
(0.9)\end{array}$ & $\begin{array}{l}13.0 \\
(1.1)\end{array}$ & $\begin{array}{c}4.1 \\
(0.5)\end{array}$ & & & & & & \\
\hline & & & & \multicolumn{4}{|c|}{ Cows culled/total cows (quartiles) } & & & & & & \\
\hline & & & & $<0.17$ & $\geq 0.17,<0.27$ & $\geq 0.27,<0.30$ & $\geq 0.30$ & & & & & & \\
\hline \multirow{2}{*}{ F-Swelling } & & & & \multicolumn{4}{|c|}{ Farm average production/cow per yr (L, quartiles) } & & & & & & \\
\hline & & & & $<7,328$ & $\geq 7,328,<8,079$ & $\geq 8,079,<8,753$ & $\geq 8,753$ & & & & & & \\
\hline \multirow[t]{3}{*}{ F-Swelling } & 4.69 & 3 & 0.003 & $\begin{array}{c}4.2 \\
(0.7)\end{array}$ & $\begin{array}{c}5.4 \\
(0.8)\end{array}$ & $\begin{array}{l}12.0 \\
(0.9)\end{array}$ & $\begin{array}{c}12.2 \\
(1.0)\end{array}$ & & & & & & \\
\hline & & & & \multicolumn{4}{|c|}{ Feed face length per cow (m, quartiles) } & & & & & & \\
\hline & & & & $<0.47$ & $\geq 0.47,<0.54$ & $\geq 0.54,<0.60$ & $\geq 0.60$ & & & & & & \\
\hline \multirow[t]{3}{*}{ F-Swelling } & 4.05 & 3 & 0.007 & $\begin{array}{c}9.5 \\
(1.2)\end{array}$ & $\begin{array}{l}11.5 \\
(0.8)\end{array}$ & $\begin{array}{l}7.7 \\
(0.7)\end{array}$ & $\begin{array}{c}7.6 \\
(1.1)\end{array}$ & & & & & & \\
\hline & & & & \multicolumn{10}{|c|}{ Lactation number } \\
\hline & & & & 1 & 2 & 3 & 4 & 5 & 6 & 7 & 8 & 9 & $10+$ \\
\hline F-Damage & 3.6 & 9 & 0.057 & $\begin{array}{l}66.9 \\
(1.4)\end{array}$ & $\begin{array}{c}60.1 \\
(1.6)\end{array}$ & $\begin{array}{l}62.0 \\
(1.9)\end{array}$ & $\begin{array}{l}61.4 \\
(2.3)\end{array}$ & $\begin{array}{l}63.1 \\
(2.8)\end{array}$ & $\begin{array}{l}67.0 \\
(3.4)\end{array}$ & $\begin{array}{l}67.4 \\
(4.5)\end{array}$ & $\begin{array}{c}67.2 \\
(5.2)\end{array}$ & $\begin{array}{c}70.0 \\
(10.5)\end{array}$ & $\begin{array}{c}83.3 \\
(17.0)\end{array}$ \\
\hline SY-Damage & 6.05 & 6 & 0.001 & $\begin{array}{l}21.5 \\
(1.9)\end{array}$ & $\begin{array}{c}30.1 \\
(2.4)\end{array}$ & $\begin{array}{c}35.3 \\
(3.1)\end{array}$ & $\begin{array}{l}30.0 \\
(3.4)\end{array}$ & $\begin{array}{c}31.9 \\
(4.0)\end{array}$ & $\begin{array}{l}41.9 \\
(5.8)\end{array}$ & $\begin{array}{l}41.9 \\
(9.0)\end{array}$ & & & \\
\hline
\end{tabular}

\footnotetext{
${ }^{1}$ Free-stall hock damage model: sensitivity $=0.85$, specificity $=0.85$; free-stall hock swelling model: sensitivity $=0.71$, specificity $=0.71$;
} straw-pen hock damage model: sensitivity $=0.66$, specificity $=0.67$.

${ }^{2}$ Passageway cleanliness was scored on a scale from 1 (very clean) to 5 (very dirty). 
Table 5. Factors affecting hock damage in organic or nonorganic farms during the fall/spring (F/S) or winter $(\mathrm{W})^{1}$

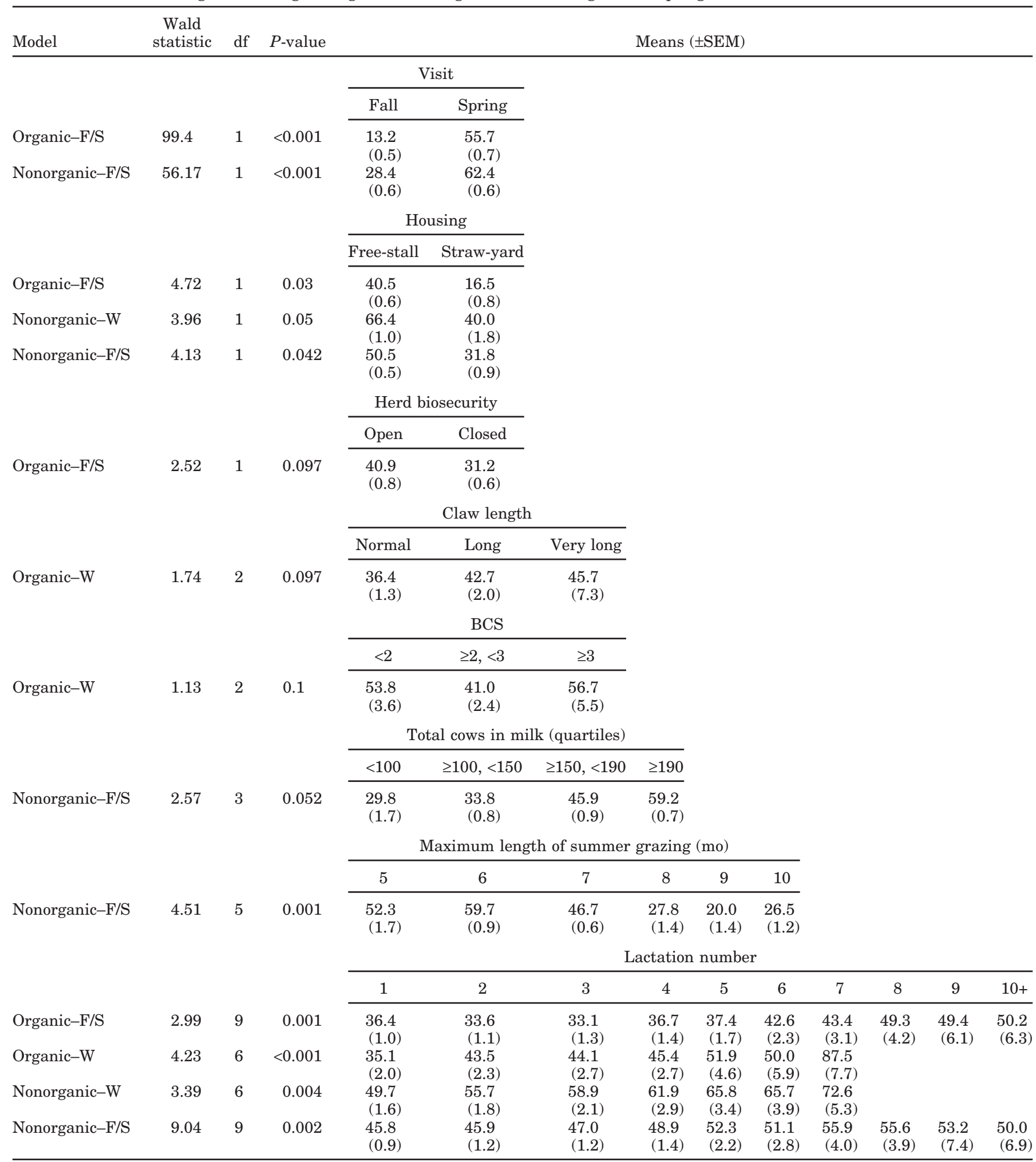

${ }^{1}$ Organic-W hock damage model: sensitivity $=0.66$, specificity $=0.68 ;$ organic $-\mathrm{F} / \mathrm{S}$ hock damage model: sensitivity $=0.69$, specificity $=$ 0.68 ; nonorganic-W hock damage model: sensitivity $=0.66$, specificity $=0.67$; nonorganic $-\mathrm{F} / \mathrm{S}$ hock damage model: sensitivity $=0.68$, specificity $=0.70$. 
for a herd improved over each period of summer pasture grazing, this could reflect an accumulation of damage in older individuals. Alternatively, older animals may be less physically agile and thus, experience more injuries when rising and lying.

In the fall/spring assessments on all 80 farms, cows with greater milk yield showed more hock damage. Sogstad et al. (2007) found that milk yield was greater in cows with hock lesions and suggested that this might be a consequence of larger body size in higher yielding animals. In addition, 2 factors were identified that related to hock damage and which have not been highlighted in previous studies. Cows that were first mated at an early age had more hock damage than older animals and cows on farms that were open showed hock damage. These factors suggest that farms with a more intensive production ethos had a greater prevalence of hock injuries.

For the 40 farms visited during the winter housing, a larger array of measures relating to housing conditions was taken. Only one of these (feed face length per cow) affected hock condition when both straw-pen and freestall farms were included in the analysis. Cows on farms with less space per cow showed more hock damage. In only the free-stall farms visited during winter housing, some additional factors were found associated with hock damage. Farms with dirty passageways or a smaller total standing area per cow had more cows with hock damage. Free-stall bedding affected hock damage, with cows on sawdust bedding having more hock lesions than those on straw bedding. These factors all support the previous evidence that cow comfort is reduced when housing conditions are poor.

There were few differences in risk factors between organic and nonorganic farms. The number of months of summer grazing, which had a highly significant impact in the main model, was only significant within the nonorganic model. Because organic herds kept their cows out for longer (our unpublished data), there was less variation in grazing duration within organic herds. Nevertheless, this variable was one of the factors explaining the lower level of hock injury within the organic farms. The organic vs. nonorganic difference seems largely explained by a cluster of factors that relate to farm production intensity. Organic management places less emphasis on maximizing productivity, and organic farmers can maintain profitability at a lower production level because of the premium for organic milk.

The analysis revealed interesting relationships between farm characteristics and the resulting hock condition of the cows within the herd. For instance, farms where heifers were mated very early had more hock damage than those where first mating was delayed.
The list of 7 factors found significant related to hock damage in the fall/spring visits to all study farms was identical to the list of variables influencing herd lameness prevalence on the same farms (Rutherford et al., accepted), suggesting much commonality between factors causing damage to the hoof and the leg. In this and other studies, hock lesions were often associated with several other cow traits indicating reduced welfare such as lameness (Klaas et al., 2003; Whay et al., 2003; Regula et al., 2004), hollow rumen, nonhock injuries (Whay et al., 2003), SCC (Fulwider et al., 2007), clinical mastitis, and teat injuries (Sogstad et al., 2006).

Expert opinion defined intervention levels (i.e., the level of prevalence of each problem at which action should be taken to remedy the problem) for different welfare-related cow traits (Main et al., 2003b). That level was $22.2 \%$ for hock hair loss (equivalent to the hock damage category), and the present study and other reported studies (Weary and Taszkun, 2000; Haskell et al., 2006) found that lesions occur at a higher level, suggesting that the general level of hock injury in the dairy cow population is unacceptably high, particularly in free-stall housing systems. Epidemiological studies can suggest possible changes that could be made to farm management to improve the level of hock injuries. The wider use of straw as a bedding (either in open yards or in free-stalls) is highly beneficial. Sand as a substrate is rarely used in the UK, and so was not assessed, but other studies have shown its benefits (Weary and Taszkun, 2000). Maximizing the duration of summer grazing would have a substantial impact on cow hock injuries.

\section{CONCLUSIONS}

Hock damage was found in a large proportion of dairy cows. Although the extent to which such damage affects animal welfare is uncertain, a high farm prevalence of hock damage suggests that cow comfort was compromised. Organic management was beneficial for cow welfare, because it reduced cow hock damage. Yet, other farm characteristics such as housing type had a substantial impact on cow hock condition. Understanding the factors that cause hock injury can help farmers reduce the level of such injuries in their herds.

\section{ACKNOWLEDGMENTS}

We would like to thank all the farmers who participated in the study. This project was funded by the UK Department for the Environment, Food and Rural Affairs (Defra). Statistical advice was provided by Ian Nevison, of Biomathematics and Statistics Scotland (BioSS). We would like to thank the following for access 
to their farmer membership lists: Organic Milk Suppliers Co-Operative, Scottish Organic Producers Association, The Soil Association, and Kingshay Farming Trust.

\section{REFERENCES}

CEC (Commission of the European Communities). 2004. Consolidated text (01/05/04) of Council Regulation No. 2092/91 on organic production. Off. J. L 198:1-15.

Drissler, M., M. Gaworski, C. B. Tucker, and D. M. Weary. 2005. Freestall maintenance: Effects on lying behavior of dairy cattle. J. Dairy Sci. 88:2381-2387.

Fayers, P. M., and D. J. Hand. 2002. Causal variables, indicator variables and measurement scales: An example from quality of life. J. R. Stat. Soc. Ser. A Stat. Soc. 165:233-261.

Fulwider, W. K., T. Grandin, D. J. Garrick, T. E. Engle, W. D. Lamm, N. L. Dalsted, and B. E. Rollin. 2007. Influence of free-stall base on tarsal joint lesions and hygiene in dairy cows. J. Dairy Sci. 90:3559-3566.

Haskell, M. J., L. J. Rennie, V. A. Bowell, M. J. Bell, and A. B. Lawrence. 2006. Housing system, milk production, and zero-grazing effects on lameness and leg injury in dairy cows. J. Dairy Sci. 89:4259-4266.

Klaas, I. C., T. Rousing, C. Fossing, J. Hindhede, and J. T. Sorensen. 2003. Is lameness a welfare problem in dairy farms with automatic milking systems? Anim. Welf. 12:599-603.

Livesey, C. T., C. Marsh, J. A. Metcalf, and R. A. Laven. 2002. Hock injuries in cattle kept in straw yards or cubicles with rubber mats or mattresses. Vet. Rec. 150:677-679.
Main, D. C. J., H. R. Whay, L. E. Green, and A. J. F. Webster. 2003a. Effect of the RSPCA Freedom Food scheme on the welfare of dairy cattle. Vet. Rec. 153:227-231.

Main, D. C. J., H. R. Whay, L. E. Green, and A. J. F. Webster. 2003b. Preliminary investigation into the use of expert opinion to compare the overall welfare of dairy cattle farms in different assurance schemes. Anim. Welf. 12:565-569.

Regula, G., J. Danuser, B. Spycher, and B. Wechsler. 2004. Health and welfare of dairy cows in different husbandry systems in Switzerland. Prev. Vet. Med. 66:247-264.

Rutherford, K. M. D., F. M. Langford, M. C. Jack, L. Sherwood, A. B. Lawrence, and M. J. Haskell. Lameness prevalence and risk factors in organic and nonorganic dairy herds in the United Kingdom. Vet. J. doi:10.1016/j.tvj1.2008.03.015

Singh, S. S., W. R. Ward, K. Lautenbach, and R. D. Murray. 1993. Behaviour of lame and normal dairy cows in cubicles and in a straw yard. Vet. Rec. 133:204-208.

Sogstad, A. M., O. Østerås, and T. Fjeldaas. 2006. Bovine claw and limb disorders related to reproductive performance and production diseases. J. Dairy Sci. 89:2519-2528.

Sogstad, A. M., O. Østerås, T. Fjeldaas, and A. O. Refsdal. 2007. Bovine claw and limb disorders at claw trimming related to milk yield. J. Dairy Sci. 90:749-759.

Thomsen, P. T., S. Østergaard, J. T. Sørensen, and H. Houe. 2007. Loser cows in Danish dairy herds: Definition, prevalence and consequences. Prev. Vet. Med. 79:116-135.

Weary, D. M., and I. Taszkun. 2000. Hock lesions and free-stall design. J. Dairy Sci. 83:697-702.

Wechsler, B., J. Schaub, K. Friedli, and R. Hauser. 2000. Behaviour and leg injuries in dairy cows kept in cubicle systems with straw bedding or soft lying mats. Appl. Anim. Behav. Sci. 69:189-197.

Whay, H. R., D. C. J. Main, L. E. Green, and A. J. F. Webster. 2003. Assessment of the welfare of dairy cattle using animal-based measurements: Direct observations and investigation of farm records. Vet. Rec. 153:197-202. 